\title{
Main Factors and Countermeasure Analysis on Teachers' Burnout in Vocational Colleges
}

\author{
Yonghong YUE ${ }^{1}$, Wenzhuo ZHANG ${ }^{2}$, Lingling SUN $^{3}$, sha XU $^{4}$ \\ ${ }^{1}$ Department of Information Science and Engineering Hebei Vocational College of Labour Relations, Shijiazhuang, Hebei, \\ ${ }^{2}$ Department of Mechanical and Electrical Engineering Hebei College of Industry and Technology, Shijiazhuang, Hebei, China \\ ${ }^{3}$ Experimental School of Shijiazhuang No.2 Middle School, Shijiazhuang, Hebei, China \\ ${ }^{4}$ Department of Information Science and Engineering Hebei Vocational College of Labour Relations, Shijiazhuang, Hebei, \\ China \\ (yueyh@126.com) (azhwenhuo@126.com) (beheisll@totmail.com) (xushasha365@163.com)
}

\begin{abstract}
- 150 teachers and 60 students in six vocational colleges of the south College District, Shijiazhuang City, Hebei Province are sampled and the professional burnout questionnaires and interviews are carried out. According to statistical analysis, it is found that more than $60 \%$ of vocational teachers have different degrees of burnout. The important factors in Vocational Teachers' Burnout include sex, age, professional title, seniority, work load and teacher-student relationships. Today, teachers' burnout in Polytechnic Colleges is growing serious and has become an important factor restricting the development of higher vocational education. Therefore, taking active and reasonable measures of vocational colleges teachers' burnout is the must.
\end{abstract}

Index Terms- Vocational Colleges teachers, job burnout

\section{Introduction}

"Burnout" is a term that was first used in the mental health field. In 1970s, American psychoanalyst Freudenberger pointed out in a book named Occupational Psychology that burnout is the physiological formidable changes arising from the weary and exhausted state of an individual who works under pressure in dealing with the outside world. Subsequently, Maslach et al proposed that burnout is posed by three dimensions, namely, a failure in spirit, dehumanization and low personal accomplishment. Emotional exhaustion is mainly expressed as individual emotion in a state of extremely fatigue and almost loss of enthusiasm; non-human performance is expressed as negative, insensitive attitude towards the people around; low personal accomplishment is expressed as low evaluation on the value and meaning of their work, the decreased confidence in the self-efficacy, the loss of enthusiasm and a sense of accomplishment, and having no desire to make efforts.

The teaching profession has its own characteristics, mainly through the establishment of a close relationship with students and play a role in helping students learn, and grow, which needs arduous labor. The teachers in vocational colleges is a special part of vocational expertise. Technology is replaced fast, the quality of students has decreased, as well as the students' reserved knowledge, learning motivation and interest are generally low. And therefore, higher vocational colleges teachers are faced with the pressure of increasingly complex work content, with little harvest. Individual potential is difficult to fulfil, resulting in some teachers' poor morale, being complacent, losing interest in work, treating their students with passive indifference, or even hoping for an early retirement, which seriously affects the stability and construction work of teachers of vocational schools.

\section{Subjects and Methods}

This study used random sampling methods and 150 questionnaires are distributed among the teachers of six vocational colleges, Shijiazhuang City, Hebei Province, 146 of which are returned, so the rate of validity is $97.3 \%$. Questionnaire consists of two parts and the first part is about the teachers' personal information, including gender, age, seniority, professional title, education, marital status, the amount of teaching assignment per week, the number of courses taught this semester, teacher-student relationship, scientific research and other 10 content; the second part is about the Table of Maslach Burnout Inventory revised for teachers (MBI-ES), which has 22 questions of the CPC and contains three sub-scales, including nine questions about "emotional exhaustion", 5 questions about "depersonalization " eight questions about "personal accomplishment". It uses scoring method, a "1" to "7" which accordingly shows "strongly disagree, disagree, somewhat disagree, neutral, somewhat agree, agree and strongly agree." Teachers samples are shown in Table 1.

\section{Causes of statistical results}

In this study, SPSS20.0 statistical software and Excell2007 are used for data analysis and process. Through testing, the results are reliable and valid. According to statistics it is found that the average level of teachers' burnout in higher vocational colleges is about 3.19, low personal accomplishment is about 4.97, emotional exhaustion is about 3.58 , inhumanity is about 2.65. Specific number distributes as shown in Table 2. 
TABLE I Constitution of sample of teachers

\begin{tabular}{|c|c|c|c|c|}
\hline Name & \multicolumn{2}{|c|}{ classification } & number & Percentage $(\%)$ \\
\hline \multirow{2}{*}{ Sex } & \multicolumn{2}{|c|}{ Male } & 37 & 25.3 \\
\hline & \multicolumn{2}{|c|}{ Female } & 109 & 74.7 \\
\hline \multirow{4}{*}{ Age } & \multicolumn{2}{|c|}{ 20-29years old } & 20 & 13.7 \\
\hline & \multicolumn{2}{|c|}{$30-39$ years old } & 85 & 58.2 \\
\hline & \multicolumn{2}{|c|}{$40-49$ years old } & 25 & 17.1 \\
\hline & \multicolumn{2}{|c|}{ More 50 years old } & 16 & 11.0 \\
\hline \multirow{4}{*}{ Labour age } & \multicolumn{2}{|c|}{$<5$ years } & 29 & 19.9 \\
\hline & \multicolumn{2}{|c|}{ 5-10years } & 73 & 50.0 \\
\hline & \multicolumn{2}{|c|}{ 10-15years } & 31 & 21.2 \\
\hline & \multicolumn{2}{|c|}{ More 15years } & 13 & 8.9 \\
\hline \multirow{3}{*}{ Position } & \multicolumn{2}{|c|}{ Primary } & 46 & 31.5 \\
\hline & \multicolumn{2}{|c|}{ Middle-level } & 81 & 55.5 \\
\hline & \multicolumn{2}{|c|}{ High-level } & 19 & 13.0 \\
\hline \multirow{3}{*}{ Educatin } & \multicolumn{2}{|c|}{ Undergraduate course } & 37 & 25.3 \\
\hline & \multicolumn{2}{|c|}{ Master's degree } & 103 & 70.5 \\
\hline & \multicolumn{2}{|c|}{ Dr. (including Dr. Being lessons) } & 6 & 4.2 \\
\hline \multirow{3}{*}{ Lessonnumber } & \multicolumn{2}{|c|}{$\leq$ 8lessons } & 21 & 14.4 \\
\hline & \multicolumn{2}{|c|}{ 9-18lessons } & 92 & 63.0 \\
\hline & \multicolumn{2}{|c|}{$\geq 19$ lessons } & 33 & 22.6 \\
\hline \multirow{4}{*}{ Lesson number } & \multirow{3}{*}{ Professional teachers } & 1lesson & 5 & 3.4 \\
\hline & & 2lessons & 21 & 14.4 \\
\hline & & $\geq 3$ lessons & 109 & 74.7 \\
\hline & \multicolumn{2}{|c|}{ Teachers with double responsibilities } & 11 & 7.5 \\
\hline
\end{tabular}

TABLE2 statistical analysis on distribution of teachers' burnout in vocational colleges

\begin{tabular}{|l|l|l|l|l|l|l|}
\hline & Good & General & \multicolumn{2}{l|}{ Bad } \\
\cline { 2 - 7 } & number & Percentage (\%) & number & Percentage (\%) & number & Percentage (\%) \\
\hline Emotional exhaustion & 49 & 33.3 & 87 & 59.6 & 10 & 7.1 \\
\hline $\begin{array}{l}\text { Low personal } \\
\text { accomplishment }\end{array}$ & 71 & 48.9 & 74 & 50.4 & 1 & 0.7 \\
\hline Depersonalized & 98 & 67.1 & 36 & 24.8 & 12 & 8.1 \\
\hline Occupational tired Overall tired & 52 & 35.9 & 93 & 63.4 & 1 & 0.7 \\
\hline
\end{tabular}

1. "Good" means the level $\leq 5 ; 2$. "General" means $3<$ the level $<5 ; 3$. "Bad" means the level $\geq 5$

Table 2 shows that teachers' burnout in higher vocational colleges starts as low personal accomplishment, then emotional exhaustion, and eventually non-human. In general, a certain degree of burnout exists among $63.4 \%$ of vocational teachers, and $0.7 \%$ of vocational teachers present more serious burnout. Teacher's gender, age, seniority, professional title, marital status, and teaching assignments have a significant correlation with the degrees of burnout and various factors can be qualitatively analyzed as follows:

\section{A Gender is a factor in the formation of teacher burnout}

Statistics show that the female teachers present more serious emotional exhaustion phenomenon than male teachers, since in addition to undertaking tasks, female teachers also bear more onerous family mission than male teachers.

\section{B Age has an effect on teachers burnout}

According to the survey results it is found that, compared with other age groups, 30-39-year-old teachers have the most obvious state of emotional exhaustion, which is the consequence of the fact that teachers in this age not only have the responsibility of taking care of young children and family, but also serve as the mainstay of the units bearing the heavy task of teaching and the pressure of professional titles, little time and effort to adapt, and so are more vulnerable to low self-esteem, exhausted condition.

\section{Professional titles also affect the teachers' burnout}

The emotional exhaustion, depersonalization performance of teachers with junior titles are higher than those of other professional teachers, and teachers with senior titles are better than other grade teachers in non-human, emotional exhaustion and personal accomplishment. Today, job classification has become a huge stress source of vocational teachers because their workload is much heavier than colleges teachers, with relatively poor research environment. At the same time, the teachers are mostly at thirty to forty years old, and therefore, prone to have the symptoms such as fatigue, apathy, selfdenial. 
D Marital status is also an important factor in the impact of teachers' burnout

Because of the dual pressures of family and work, married teacher are more likely to feel weary, and therefore, the levels of their emotional exhaustion, depersonalization are significantly higher than the unmarried ones.

\section{E Teaching load most affects teachers' job burnout}

Teaching workload can be shown in two aspects: the amount of tecaching assignment and the courses a teachers has to teach.

1) The teaching workload of vocational teachers is very large: $63.0 \%$ of teachers have to give 9-18 classes per week, and $22.6 \%$ of teachers meet and exceed 19 classes per week (including the capacity of part-time work off-campus). The more classes a teacher has, the more arduous preparation has to be done before classes. Before classes, teachers need spend a lot of time consulting teaching materials, and teaching load has a positive correlation with the preparation load. Besides, in the teaching process, teachers need put a lot of energy and enthusiasm to achieve better teaching results. More teaching load needs teachers' more energy and stamina. Additionally, the current era is a time rapid changes happen in vocational education, so teachers under great pressure need to constantly innovate and reform the traditional teaching model. [1]

2) In addition to a heavy workload, teachers have to assume more teaching tasks of many courses: According to the survey, $74.7 \%$ of vocational teachers undertake teaching tasks of 3 courses or more, in which more than $80 \%$ of teachers have had varying degrees of burnout problems.

In order to ensure the number of students, vocational college constantly update curriculums. Many vocational colleges were upgraded over the past decade from the secondary schools, and has not yet formed its own school characteristics, professional groups, and curriculum. They often create departments where the recruitment is easy or the gratuates can easily get a job, which results in the fact that the departments are replaced extremely frequently. At the same time, in order to meet the needs of teaching, many teachers undertake the teaching tasks of the large professional span and have the tremendous pressure of pre-class preparation. In addition, vocational education is "to focus on service for the society, to emphasize the employment of students". It trains the highskilled practical talents who are needed on the first line of production, construction, service and management. Teachers in vocational colleges not only have rich solid professional knowledge, but also have good practical skills that meet the "double qualified" requirement. Therefore, specialized teachers suffered heavy physical and psychological burden of preparing lessons, classes, and practical operations. This kind of monotonous, repetitive working conditions, the constant work pressure, and high working load, can easily cause teachers' burnout higher.

F Students of varying quality, and students' increasingly lower enthusiasm and interest also result in the teachers' burnout

In order to fully understand the phenomenon of vocational teachers' burnout, the author also take a sample of 60 students from three vocational colleges to conduct interviews, which mainly contains four questions. First, do you like the major you are enrolled in? Second, are you going to be engaged in related professional job after graduation? Third, how is your class attendance, and curriculum knowledge? To what extent do you grasp the practical skills you learned? The fourth is about the communication between teachers and students. The results show that more than half of students have a serious shortage of motivation, and a poor understanding of professional knowledge, with low interest in learning. A quarter of students often skip classes. It is common to sleep, or play telephones in class. Due to lack of communication with teachers, some students even do not know the teachers' family name. Teaching ability should have improved together with the process of learning, but in face of more student problems, many teachers have the feelings of frustration, disappointment and lack enthusiasm, which resulted in their bad attitude to students with denial, numbness and laissez-faire, and then the formation of burnout.

\section{Strategy to Teachers' Burnout}

The tendency of vocational teachers' burnout, once formed, is bound to cause teachers' gradual loss of enthusiasm for the work. Over time, many teachers will reduce their investment in time and energy to seek psychological balance, which will continue to accumulate, strengthen burnout, and then seriously affect the stability and construction in a vicious circle. It has become an important factor restricting the development of higher vocational education. Therefore, taking active and reasonable measures to impose intervention and guidance to remove the burnout of vocational colleges teachers is urgent and necessory.

A Social and organizational support is a prerequisite to respond Higher Teachers' Burnout

1) From the social level: States should strive to remove the bias on vocational education as soon as possible and make the public know more about it. Vocational teachers should be put in a proper position of the society and their enthusiasm and passion should be protected by improving their treatment and social status, which is a prerequisite to deal with the burnout of vocational teaching.

2) From the college level: In scientific research, further studies, job classification and training in enterprises, colleges should provide convenient conditions and policy support for the vocational teachers, and strive to create a deep reform of vocational education. They are expected to promote healthy environment and atmosphere, provide a steady stream of momentum, and improve teachers' sense of belonging, selfrecognition and achievement on their work, which is the basic condition to deal with vocational teachers' burnout.

B Vocational college should increase understanding, respect and support to teachers, which is important to deal with the vocational teachers' burnout

1) Establish a people-centered concept with more humane 
and democratic management: College teachers should be actively encouraged to participate in decision-making development of the Institute, not only to improve their professional responsibility and establish their faith of the same fate with school, but also enhance the positive initiative of their ownership and work.

2) Strengthen the construction of campus culture to create a harmonious, positive work environment for teachers: People's state of mind is often susceptible to the surrounding environment, and good working environment will not only maintain a high teacher job satisfaction but also remove burnout. Therefore, vocational college should create a relaxed and harmonious working environment, reduce teachers' workload and optimize the construction of campus culture. Carrying out all kinds of knowledge-based, cultural, sports and entertainment activities can enrich the spiritual life of teachers and strengthen the relationship and extensive exchanges among leaders, students and teachers, resulting in the remove of work pressure.

3) Improve the incentive mechanism evaluation : Maslow's hierarchy of needs theory says the people's demand on requirement gradually transformed from the primary physiological need to a higher level of respects and selfactualization needs. Therefore, the evaluation on teachers is an important factor of teachers' burnout. Each vocational institute school should follow the law of development of education, change the concept of evaluation, and carry out a incentive system of scientific evaluation and management. Vocational college should also change the simple scoring ways by students and supervisors, reform teacher evaluation system, establish a scientific and effective work appraisal system, which combines quantitative and qualitative analysis, the teacher's job performance and a variety of factors such as the teachers' developments of their learning attitude, learning ability, learning methods, innovations, etc. [2] to make a scientific, comprehensive and effective evaluation on teachers.

C Promotinh communication and exchange between teachers and students is the central condition to deal with vocational teachers' burnout

Teacher-student relationship is an important factor affecting teachers' burnout, but now students in vocational colleges commonly have weak fundamentals and low interest in learning, with lack of initiative and exploratory. Someone even do not comply with classroom discipline and teachers, and that leads some teachers' decline in teaching accomplishment, self- evaluation on teaching performance. Therefore, increase exchanges and communication between teachers and students are very vital.

1) From school level: On one hand, colleges should carry out the forum or activities to promote exchanges between teachers and students; on the other hand, it is necessary to guide and enhance teachers' work initiative and enthusiasm for the understanding of students.
2) From vocational teachers themselves level: Teachers should take the initiative to understand the characteristics of vocational students, fully accept and respect students by updating the content of education from the student's point of view, or changing teaching methods. Vocational College are to train specific talents with high skills for the production, construction, management, service on the first line. So they need gradually shift from theory-based teaching to actionbased teaching, improve students' interest in learning and have a better understanding the needs of students by training in enterprises and the reform of the "Work Integrated Learning" mode. Teachers should not treat their students out of the understanding of the undergraduate and graduate students in their own period with a negation attitude or complaints, but should develop together with the students.

D That vocational colleges teachers learn selfcommissioning and management is the key condition to deal with job burnout

In everyday teaching process, burnout circumstances of each vocational teachers are different, so the characteristics of teachers themselves are important factors to result in burnout, which means that vocational teachers learn self-commissioning and management is the key condition to deal with Burnout. Vocational teachers should learn to work during rest, do more physical exercise and enrich amateur life. The appropriate involvement of psychological decompression and counseling activities can take the initiative to ease their work stress, relax work state, and gradually improve the feeling of self-efficacy in teaching.

\section{Conclusion}

150 teachers and 60 students in six vocational colleges of the south College District, Shijiazhuang City, Hebei Province are sampled and the professional burnout questionnaires and interviews are carried out. According to statistical analysis, it is found that more than $60 \%$ of vocational teachers have different degrees of burnout. The important factors in Vocational Teachers' Burnout include sex, age, professional title, seniority, work load and teacher-student relationships. Today, teachers' burnout in Polytechnic Colleges is growing serious and has become an important factor restricting the development of higher vocational education. Therefore, taking active and reasonable measures of vocational colleges teachers' burnout is the must.

\section{References}

[1] Chen Yuan Investigation and analysis on Chongqing Higher Teachers' Burnout factors. Chongqing College of Electronic Engineering Technology, 2013

[2] Wang Xiaojuan Teachers' Burnout from Management Perspective. Vocational Education, 2013 B. Simpson, et al, "Title of paper goes here if known," unpublished. 